\title{
Degradação do lastro ferroviário - principais aspectos e estudos de caso
}

\author{
José Pires ${ }^{1}$, Robson Costa ${ }^{2}$, Liedi Bernucci ${ }^{3}$, Rosângela Motta ${ }^{4}$, Edson de Moura ${ }^{5}$ \\ 1Escola Politécnica da Universidade de São Paulo, USP, eng.josejoao@gmail.com \\ 2Escola Politécnica da Universidade de São Paulo, USP, costa.robsonc@gmail.com \\ ${ }^{3}$ Escola Politécnica da Universidade de São Paulo, USP, liedi@usp.br \\ 4Escola Politécnica da Universidade de São Paulo, USP, rosangela.motta@usp.br \\ ${ }^{5}$ Escola Politécnica da Universidade de São Paulo, USP, edmoura@usp.br
}

\section{Recebido:}

06 de março de 2016

Aceito para publicação:

13 de outubro de 2017

Publicado:

29 de outubro de 2017

Editor de área:

Jorge Barbosa Soares

\section{Palavras-chaves:}

Lastro ferroviário,

Degradação do lastro ferroviário,

Superestrutura ferroviária.

\section{Keywords:}

Railway ballast,

Ballast degradation,

Railway superstructure.

DOI:10.14295/transportes.v25i3.1340

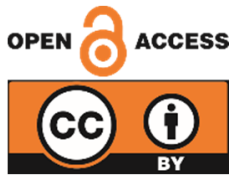

\begin{abstract}
RESUMO
A camada de lastro é considerada como um dos mais importantes elementos de um perfil estrutural ferroviário, exercendo um papel singular no comportamento mecânico deste. Devido ao tráfego e aos procedimentos de manutenção, ao longo do tempo, o lastro tende a se degradar. O objetivo deste artigo é avaliar a evolução da degradação do lastro por meio de parâmetros como granulometria, Coeficiente de Não Uniformidade (CNU), forma e seus distintos modos de degradação. Adicionalmente, apresentase uma visão geral referente à deterioração do lastro e, dentro deste contexto, dois estudos baseados em ensaios laboratoriais de degradação por abrasão, em conjunto com um procedimento que considera imagens dos grãos e o cisalhamento destes. De maneira geral, este artigo mostra diferentes modos de degradação e uma adequada representação qualitativa da evolução da degradação dos grãos através dos métodos utilizados baseados em ensaio de abrasão com obtenção de imagens e de cisalhamento.
\end{abstract}

\begin{abstract}
The ballast layer of a railway structural profile is considered one of the most important elements of the railway structure having a singular role on its mechanical behavior. Due to traffic and maintenance actions, over time, the ballast material tends to degrade. The objective of the paper is to evaluate the ballast degradation evolution in terms of gradation (Non-Uniformity Coefficient), shape and its distinct modes. This paper presents a review concerning ballast degradation and two studies based on degradation laboratory tests in terms of abrasion within an image-based procedure and shearing tests. Generally, the paper showed different degradation modes and an adequate representation of the grains degradation evolution via methods based on abrasion tests with images obtainment and shearing.
\end{abstract}

\section{INTRODUÇÃO}

O lastro é a camada granular superior do que se considera como superestrutura ferroviária, sendo composta por grãos cúbicos, graduados entre as frações 12,0 e 63,0 mm, em condição compactada e tendo vazios associados. A camada de lastro tem funções relacionadas à resistência, deformabilidade e drenagem, de maneira a proporcionar uma "fundação" sólida para a grade ferroviária, drenagem adequada, distribuição uniforme das tensões e também à flexibilidade, além de permitir a reconstituição do nivelamento vertical no sentido longitudinal e fornecer absorção de ruídos e vibração (Selig e Waters, 1994).

A capacidade do lastro de realizar suas funções é determinada pelo estado físico do conjunto granular e pelas características dos grãos em termos de tamanho, formato, resistência, etc. Oda e Iwashita (1999) argumentam que o comportamento dos materiais granulares é determinado pelo arranjo das partículas e características interpartículas, enquanto que Raymond (1985) comenta que as características geométricas dos grãos são de ímpar importância para a estabilidade da via. 
Com o intuito de orientar a respeito da adequabilidade do material do lastro, diferentes normas mencionam a respeito da granulometria a ser utilizada. As Figuras 1 e 2 mostram, respectivamente, exemplos de faixas granulométricas referentes às normas utilizadas para o lastro em ferrovias de alta carga no Brasil (VALE) e EUA (AREMA) e de passageiros na Europa e Suíça (SN 670110 e CFF R211, respectivamente) e os devidos coeficientes de gradação (Coeficiente de Não Uniformidade, $C N U=\mathrm{D}_{60} / \mathrm{D}_{10}$; e Coeficiente de Curvatura, $C C=D_{30}{ }^{2} / D_{60} . D_{10}$, onde $D_{60}, D_{30}$ e $D_{10}$ representam o valor referente a 60,30 e $10 \%$ de material passante na curva granulométrica). A importância de tais coeficientes reside no fato dos mesmos indicarem a amplitude do tamanho dos grãos. Em relação aos valores de CNU, no que concerne à degradação, Indraratna et al. (2011) citam que as especificações de lastro de diferentes países normalmente utilizam um intervalo de CNU entre aproximadamente 1,5 e 3,0. Estes concluíram que os lastros uniformemente graduados sofrem maiores deslocamentos e são mais vulneráveis à quebra, em comparação com lastros bem graduados.

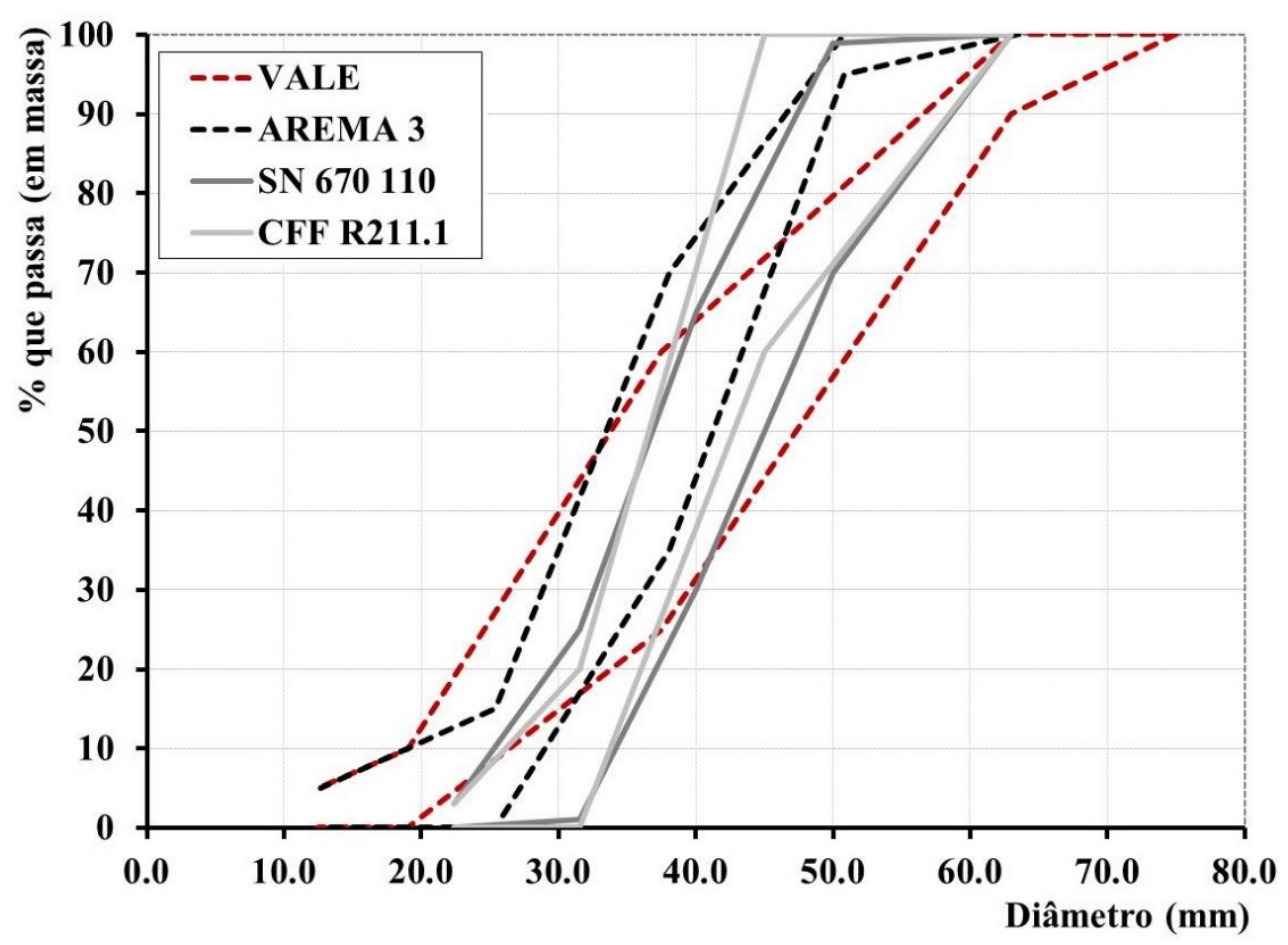

Figura 1. Curvas granulométricas do lastro, segundo diferentes normas

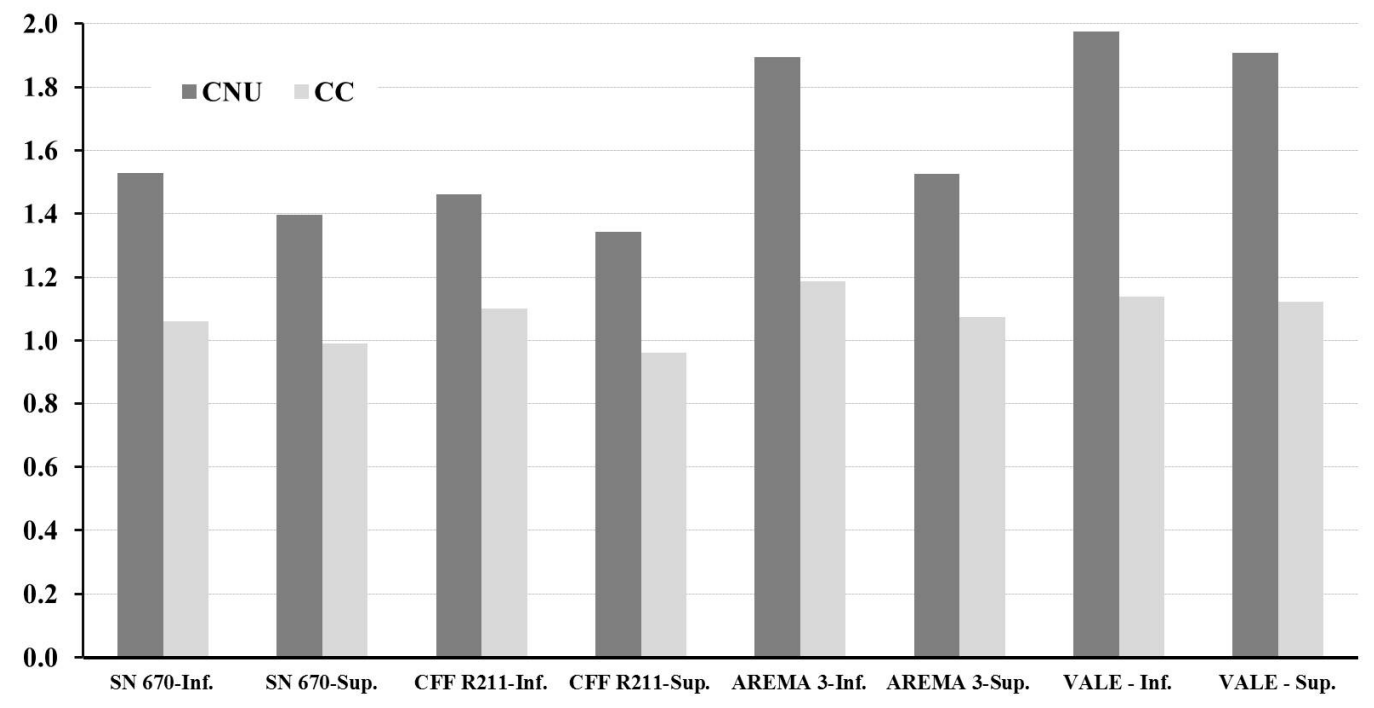

Figure 2. Coeficientes de gradação, segundo diferentes normas 


\section{DEGRADAÇÃO DO LASTRO FERROVIÁRIO}

Os grãos de lastro interagem naturalmente entre si, criando pontos de contato. Em função das magnitudes das tensões, acumulação de tráfego e ações de socaria nos pontos de contato, os grãos tendem a se degradar, provocando perda de parte do desempenho mecânico da camada de lastro. Tal degradação é fator singular no comportamento mecânico do lastro, sendo associada ao esmagamento dos grãos por fenômenos relacionados ao atrito e/ou quebra, acarretando na geração de material mais fino, que tende a preencher os vazios granulares (colmatação). Assim, estudos a respeito das tendências de degradação mostram-se especialmente importantes para melhor compreensão deste mecanismo.

A colmatação da camada de lastro é causada por diferentes fenômenos, tais como degradação dos grãos, bombeamento de material fino do subleito (ou sublastro), aporte externo (material transportado), abrasão entre dormentes e grãos e intemperismo. Cabe mencionar que a origem dos finos que colmatam a camada de lastro pode ser o solo proveniente do subleito, material transportado ou mesmo poeiras externas.

As fontes de colmatação são diversas e podem variar de local para local, dependendo do uso da ferrovia, do tráfego e dos materiais empregados, por exemplo. Segundo Selig e Waters (1994), dados do Reino Unido mostraram as principais fontes de colmatação do lastro como sendo o aporte externo (52\%) e o dano ao grão onde se inclui o efeito da socaria (41\%). Entretanto, dados norte-americanos indicaram que a fonte maior de colmatação seria a quebra dos grãos (76\%) devido ao tráfego, manutenção, intemperismo, etc. (Figura 3). Por outro lado, particularmente em ferrovias de altas cargas ( $\geq 30,0$ t/eixo) que transportam minério de ferro, observa-se uma significante contribuição à colmatação advinda da queda do material dos vagões, a qual foi reportada por Vale (2011) e Ionescu (2005), referindo-se a ferrovias no Brasil e Austrália, respectivamente.

(a)

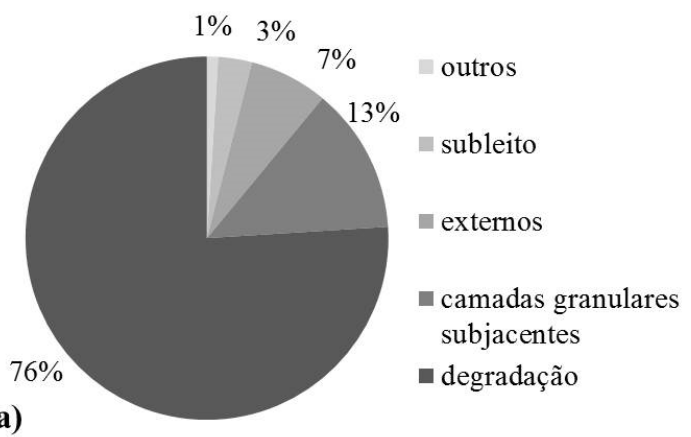

Figura 3. Fontes de colmatação do lastro nos EUA (a) e Reino Unido (b) (Selig e Waters, 1994)

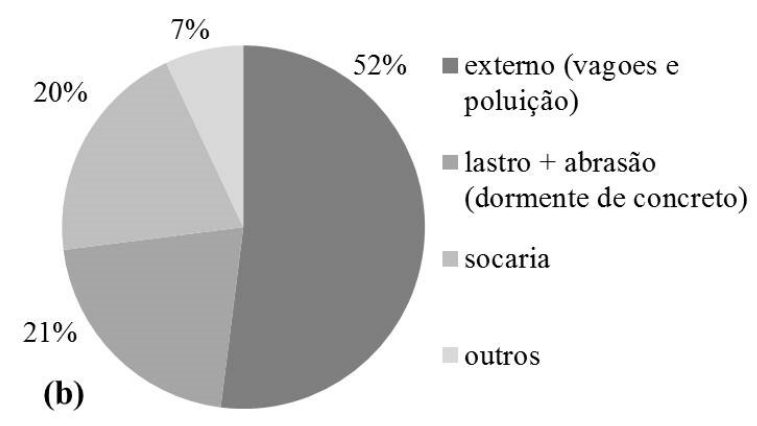

(b)

Em geral, os valores mostram um montante significativo de material que colmata o lastro por degradação dos grãos, devido ao tráfego e manutenção. A propósito, em outros estudos, desta vez conduzidos pela Association of American Railroads (AAR), verificou-se 75 a 90\% de colmatagem com material advindo da quebra de lastro, o qual foi acumulado ao longo de 300 Milhões de Toneladas Brutas Transportadas (MTBT).

De acordo com Lekarp et al. (2000), o esmagamento dos grãos é um processo progressivo, iniciandose com tensões relativamente baixas e resultando em graduais alterações na estrutura granular e na densidade do material. De acordo com Terzaghi e Peck (1962), o mecanismo de compressão de enrocamentos é o resultado do esmagamento de pontos de contato, com altos valores de tensões e o rearranjo das partículas durante a aplicação de cargas. Assim, um mecanismo similar é esperado que ocorra nos pontos de contato dos grãos de lastro, especialmente sob cargas mais altas. A Figura 4 mostra um diagrama esquemático das tensões em um material de granulometrias uniforme e melhor graduado (Gotschol, 2002 apud Neidhart e Schulz, 2011). 
a) Graduação uniforme

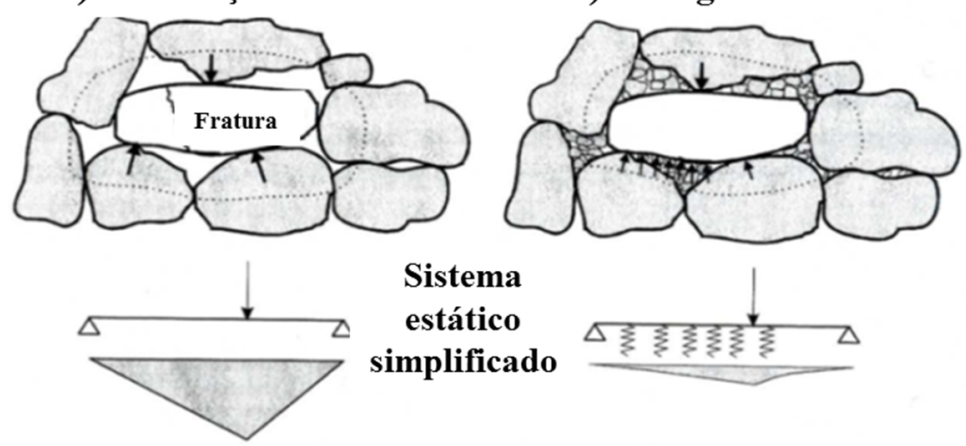

Figura 4. Diagrama esquemático das tensões nos grãos (Gotschol, 2002 apud Neidhart e Schulz, 2011)

De acordo com Indraratna e Salim (2003), a degradação do lastro depende de fatores como amplitude, frequência e número de ciclos de carga, densidade da camada, granulometria, angularidade e forma dos grãos, etc. Entretanto, o fator mais significante que governa a quebra do lastro é a resistência à fratura das suas partículas.

Tal qual o tráfego, as manutenções da geometria da via por meio das ações de socaria podem provocar considerável dano ao grão. De fato, o método é considerado como destrutivo, do ponto de vista do lastro. No entanto, tais manutenções permitem uma rápida correção da geometria, ainda que, ao mesmo tempo, tendam a degradar os grãos, especialmente durante a inserção das hastes vibratórias do equipamento. De acordo com Aursudkij (2007), as inserções das hastes tendem a quebrar grandes agregados, enquanto que a compressão dos grãos sob o dormente causa abrasão na superfície dos grãos, como ocorre durante o carregamento pelo tráfego (ambos produzem degradação menor e similar). Perales et al. (2011) concluíram que a socaria provoca tensões nos grãos mais próximas daquelas relacionadas a um choque do que um fenômeno propagado ao longo do tempo, como a abrasão. Nurmikolu (2005) cita uma pesquisa de Chrismer (1988), referente ao material de lastro submetido a tráfego e manutenção durante o período de três anos, que mostrou uma degradação significativa causada pela socaria, que mudou a granulometria mais do que o tráfego durante o período de análise.

De fato, o material do lastro pode degradar de diferentes modos. De acordo com Raymond e Diyaljee (1979), o processo de degradação dos grãos de lastro pode ocorrer de três maneiras: quebra em aproximadamente duas partes similares, quebra das projeções angulares, e esmagamento/moagem de pequenas asperezas. A Figura 5 mostra exemplos de grãos de lastro degradados por desgaste (abrasão) e quebra.

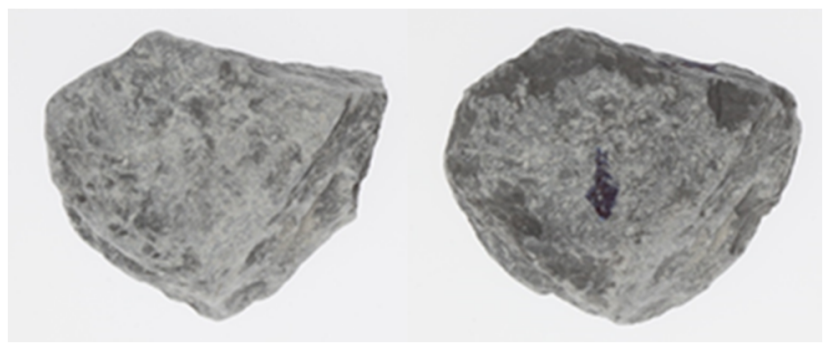

(a)

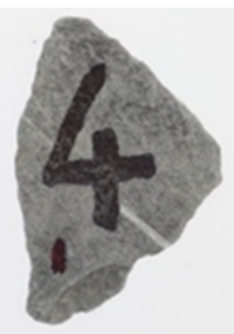

Figura 5. Degradação do lastro por abrasão (a) e quebra (b)

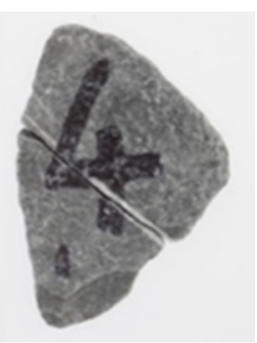

(b)

A quebra de partículas é a dissecação dos grãos ocorrendo geralmente sob altos níveis de tensões, enquanto que a abrasão é o fenômeno no qual partículas muito pequenas se desintegram da superfície do grão, independentemente dos níveis de tensões (Indraratna et al., 2011). Dentro deste contexto, Indraratna et al. (2005) identificaram que a maior parte da degradação do lastro é primariamente consequência da quebra de angularidades com considerável atrito/abrasão. 
Sob tráfego, os choques e as altas pressões induzidas pela carga distribuída através da superfície de contato entre os grãos e os dormentes criam um canal de distribuição de tensões e as concentrações destas tensões nas arestas podem provocar a sua própria quebra, além de tender a triturar/moer a porção de material de lastro, especialmente sob o dormente.

Como resultado da degradação dos grãos de lastro, diferentes frações granulares são geradas, incluindo o que é considerado material fino (menor que um diâmetro específico, por exemplo, 12,5 mm). Em geral, o valor de aproximadamente 30\% de material fino é tido como indicador de nível máximo de contaminação de uma camada de lastro, indicando um possível fim de sua vida útil (Lichtberger, 2005; Selig e Waters, 1994; Esveld, 1993).

Sob tensões advindas do tráfego e manutenções, a granulometria do lastro sofre alterações, gerando diminuição do índice de vazios/porosidade da camada. Como resultado do atrito e/ou quebra, o material fino produzido, quando somado à entrada de água, dependendo da granulometria das partículas oriundas da degradação, pode provocar o surgimento de poro-pressões negativas (sucção), acarretando alterações na resistência e na permeabilidade. Ainda, a degradação afeta a forma do grão, tendendo-o ao arredondamento, com consequências no comportamento mecânico do lastro.

Durante o processo de degradação, a evolução do formato do grão pode indicar características relacionadas ao processo de deterioração do lastro. Segundo Mvelase et al. (2012), índices geométricos como esfericidade e arredondamento podem ser utilizados para avaliar a deterioração dos grãos. 0 arredondamento é calculado como a taxa da soma dos raios referente às arestas em relação ao raio máximo do círculo inscrito, dividido pelo número de grãos avaliados (Wadell, 1932) podendo ainda ser calculado por meio dos valores de perímetro e área.

Com o intuito de simular a degradação do lastro, testes de abrasão (ensaios Los Angeles, Mill e Micro Deval) são uma importante base para a avaliação quanto a adequabilidade do material (Selig e Boucher, 1990). Além disso, testes triaxiais de grande escala (Fortunato, 2005; Ionescu, 2004) e aparatos de simulação de tráfego e socaria (Paderno, 2010; Aursudkij, 2007) têm sido utilizados para avaliar a degradação do lastro sob diferentes condições de tráfego e socaria. Estudo realizado pela AAR (1989) mostrou clara diferença na degradação entre materiais de diferentes qualidades em termos de "Abrasion Number" (AN=LAA+5MA) em função do valor de MTBT (Figura 6). Os termos LAA e MA referem-se a Los Angeles Abrasion e Mill Abrasion respectivamente.

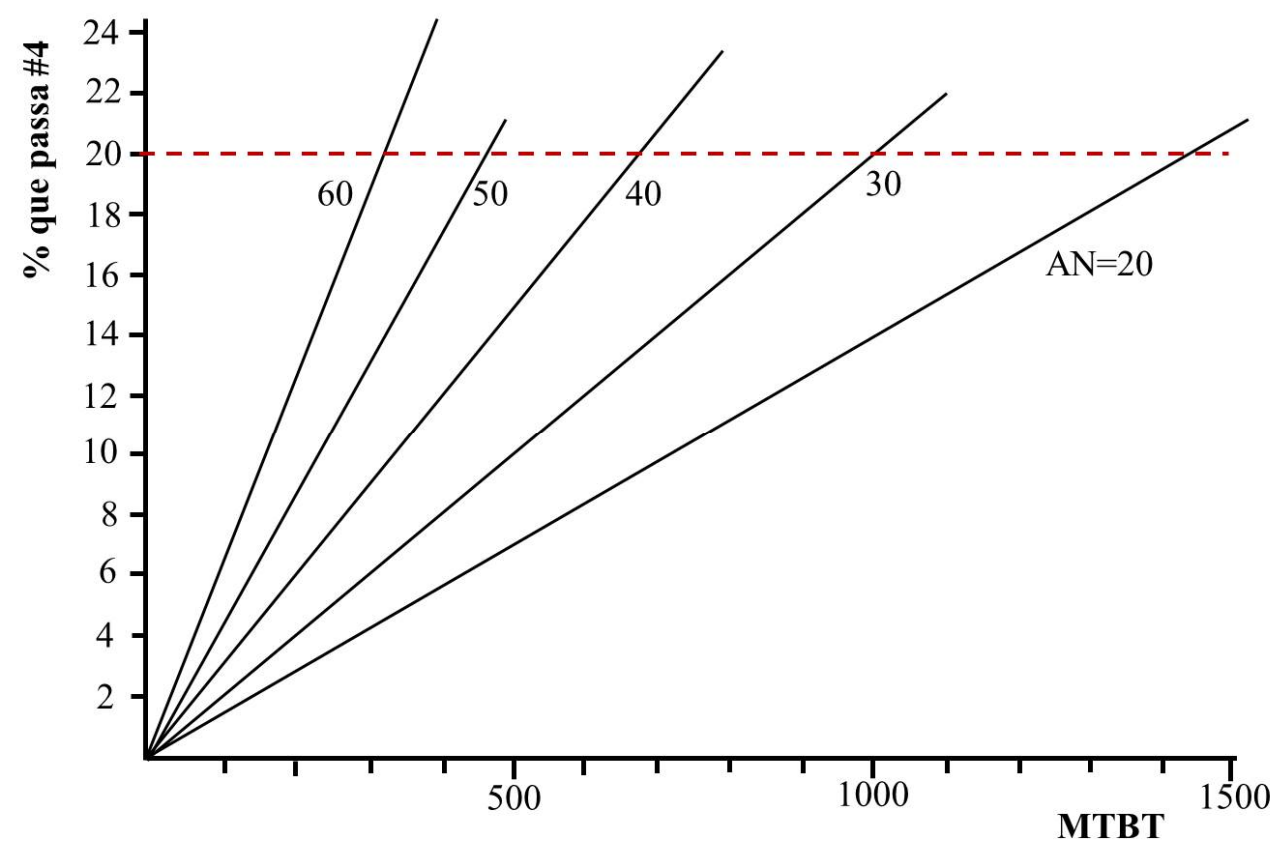

Figure 6. Degradação do lastro relacionando os valores de AN e MTBT 
Rothlisberger et al. (2006) citam a correlação entre os resultados dos ensaios de abrasão Los Angeles (LAA) com o fenômeno de abrasão induzido pelo tráfego, ao contrário da conclusão obtida por Aursudkij (2007) que associou os resultados daqueles ensaios com a degradação decorrente da socaria. 0 primeiro relata ainda que o envelhecimento do lastro é primeiramente relacionado com as ações de socaria, como observado por Aursudkij (2007) e que o ambiente crítico do lastro é limitado ao material afetado por ela.

Segundo Ruth e Tia (1998), a degradação do agregado pode ocorrer durante seu manuseio, processo de mistura, transporte e compactação, quando pode ser alterada sua gradação e, consequentemente, seu comportamento ao longo do tempo. Os autores avaliaram três graduações com valores de abrasão LAA semelhantes, submetendo-os ao Gyratory Test Machine (GTM), aplicando 25, 50, 100 e 200 giros. Os mesmos observaram diferenças quanto à energia aplicada ao comparar os ensaios, sugerindo que para uma melhor avaliação da qualidade dos agregados, se faz necessário o uso do compactador giratório. No caso da utilização deste último, devido a restrições do equipamento quanto ao diâmetro do grão, para o lastro ferroviário tem-se a necessidade de se utilizar métodos de decalagem granulométrica, a fim de adequar o material à granulometria real do mesmo. Sevi (2008), Klincevicius (2011) e Merheb (2014), por exemplo, utilizaram grãos em escala reduzida (4-25 mm) por intermédio do método da graduação paralela, a fim de se avaliar a degradação do lastro.

Nos últimos anos, métodos numéricos têm sido usados para avaliar o comportamento do lastro em degradação. Dentre estes, destacam-se os métodos de modelagem descontínuos que consideram o material como um amontoado de partículas rígidas. A corrente dominante na modelagem numérica baseada em meios descontínuos é conhecida como DEM (Discrete Element Method), cujo método é capaz de analisar múltiplos corpos em interação submetidos a deslocamentos e rotações. A detecção dos contatos e interações entre os corpos são os aspectos mais importantes do método, que se distingue pela capacidade de perceber e criar novos contatos durante o cálculo.

Objetivando representar a quebra do lastro, diferentes estratégias têm sido utilizadas como, por exemplo, a substituição de partículas por um grupo equivalente destas, a partir de um critério de falha predefinido e a consideração de cada partícula como um aglomerado poroso construído por partículas menores aglomeradas. As Figuras 7(a) e 7(b) mostram, respectivamente, exemplos de modelos de grãos de lastro, de acordo com Indraratna et al. (2010) e Lobo-Guerrero e Vallejo (2005).

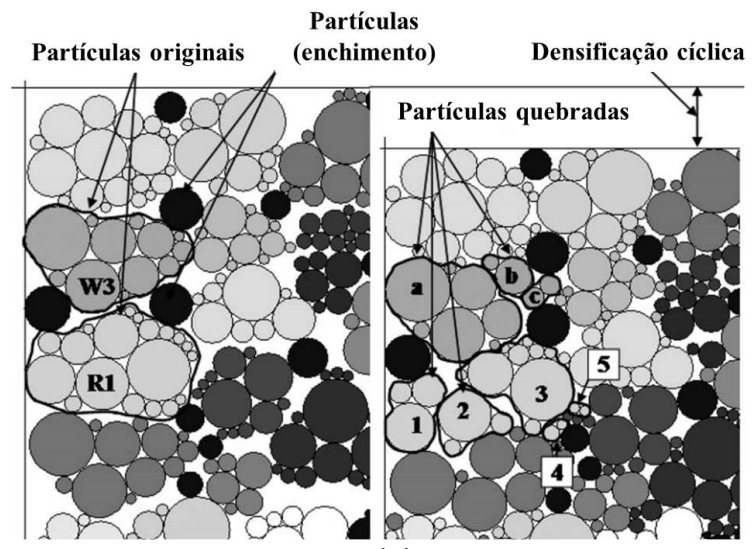

(a)

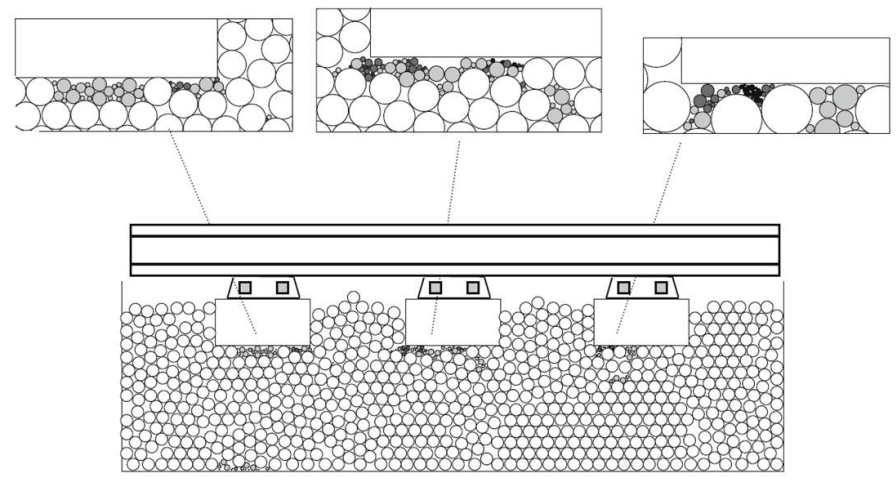

(b)

Figura 7. Porção do aglomerado de grãos mostrando quebra de partícula (a) e detalhes da representação do lastro degradado (b) em modelagem numérica (DEM)

Lobo-Guerrero e Vallejo (2005) trataram a partícula como um aglomerado poroso intuindo avaliar a evolução de degradação em um modelo representativo do lastro ferroviário, utilizando-se como critérios de degradação o número de contatos ("coordination number") e a comparação entre as tensões de tração 
calculadas e um valor limite. Em outro tipo de abordagem, Indraratna et al. (2011) realizaram um estudo do lastro submetido a carregamentos cíclicos usando-se o conceito de "parallel bonds", que representa os grãos de lastro como um aglomerado de partículas.

\section{ANÁLISE DE DEGRADAÇÃO DO LASTRO}

A fim de se estudar a evolução da degradação do lastro em diferentes condições, dois diferentes estudos foram conduzidos no presente trabalho. No primeiro, testes laboratoriais de abrasão baseados no ensaio LAA foram realizados, a fim de avaliar a evolução da degradação do lastro em função do número de giros, tendo como resultados os desvios granulométricos e a evolução do formato dos grãos. Ainda, diferentes características quanto aos modos de degradação relacionados à abrasão e à quebra foram estudadas. Em um segundo estudo, a degradação foi avaliada por meio da prensa de compactação por cisalhamento giratória (PCG), obtendo-se a variação granulométrica e a evolução dos valores dos coeficientes de gradação.

\subsection{Materiais e métodos}

\subsubsection{Ensaios de abrasão com obtenção de imagens}

O material do primeiro estudo foi um lastro coletado em uma pedreira fornecedora da empresa suíça de ferrovias (CFF/SBB). Tal material caracteriza-se por ter uma origem arenítica, com cerca de $30 \%$ de minerais duros, partículas de diâmetro entre 22,4 e 63,0 mm e valores característicos de resistência à abrasão (LAA) entre $11 \%$ e $15 \%$, estando em acordo com a norma europeia EN 13450. Nesta pesquisa a amostra foi submetida a ensaios de abrasão, baseados no ensaio LAA mediante 100, 200, 300 e 400 giros, realizados sem as esferas de aço normalmente empregadas, almejando-se evitar choques excessivos, mas promover abrasão.

Para tanto, cerca de 100 grãos foram aleatoriamente selecionados dentre as frações granulométricas referentes ao material de lastro, e numerados, a fim de manter o monitoramento de sua degradação, tendo sido capturadas as imagens dos mesmos e, posteriormente, obtida a curva granulométrica da amostra como um todo. Em seguida, a cada estágio do teste (referente a um número de giros), foram determinadas as curvas granulométricas da amostra, além de obtidas as imagens de cada um dos grãos selecionados e o seu arredondamento (Arr). Este último foi verificado através do processamento das imagens e da determinação dos valores do perímetro $(\mathrm{P})$ e área $(\mathrm{A})\left(\mathrm{Arr}=4 \pi \mathrm{A} / \mathrm{P}^{2}\right)$, referentes às imagens dos grãos pelo software Pixcavator. No tocante à obtenção das imagens, para visualização da evolução da degradação ao longo dos estágios de giros, um aparato composto de tripés, anteparos e outros, foi montado para tal finalidade. Além dos resultados relacionados à granulometria e forma dos grãos, os valores de CNU e CC foram determinados em cada estágio, a fim de se obter uma medida quantitativa da evolução da degradação do material. Deste modo, a partir da granulometria e de observações visuais em cada estágio de cada grão, os modos de degradação e principais características durante cada fase foram identificados.

\subsubsection{Ensaios em Prensa de Compactação por cisalhamento Giratório (PCG)}

0 material do segundo estudo era oriundo de uma pedreira fornecedora de lastro para a Estrada de Ferro Vitória Minas (EFVM) no Brasil. Tal material caracteriza-se por ter uma origem granítica e partículas de diâmetro entre 4,75 e 25,0 mm. No presente estudo foram empregadas as curvas granulométricas №s 3 e 24 da AREMA (2013), de modo decalado, para avaliar o desgaste do lastro ferroviário, em uma prensa de compactação por cisalhamento giratório (PCG 3 francesa). Inicialmente, as partículas foram colocadas em uma bandeja, misturadas, homogeneizadas e divididas em quatro frações, sendo cada uma disposta dentro de um molde cilíndrico com diâmetro de $150 \mathrm{~mm}$ e altura de $300 \mathrm{~mm}$. Em seguida, a amostra era densificada por meio de um peso $(8 \mathrm{~kg})$ e de uma mesa vibratória por 40 segundos até atingir a altura de ensaio $(280 \mathrm{~mm})$. 
Na prensa PCG 3, os agregados foram submetidos aos esforços de compactação por cisalhamento, a uma força axial de $11.700 \mathrm{~N}$ (valor este que corresponde a uma tensão cisalhante de $662 \mathrm{KPa}$ ), ângulo de inclinação de $1^{\circ}$ e rotação de 33 rpm. Considerou-se 100, 200, 400, 500, 600, 800 e 1000 giros, sendo que após cada estágio do teste (referente aos números de giros mencionados) foram determinadas as curvas granulométricas e valores de CNU e CC.

\subsection{RESULTADOS}

\subsubsection{Ensaios de abrasão com obtenção de imagens}

Tal como descrito foram determinadas as curvas granulométricas ao longo dos estágios de giros referentes aos ensaios de abrasão. As Figuras 8 e 9 mostram respectivamente tais curvas com os valores de CC e CNU obtidos, além da variação da distribuição granulométrica.

A Figura 8 mostra que, após 100 giros, todas as frações granulométricas foram afetadas pela degradação e a fração entre 0 e 22,4 mm já tinha montante de material fino superior ao permitido pela norma europeia $(\approx 3 \%)$. Nos subsequentes ciclos, o desvio granulométrico observado foi menor, com uma maior tendência de aumento e diminuição nas frações 0-22,4 mm e 50,0-63,0 mm, respectivamente.

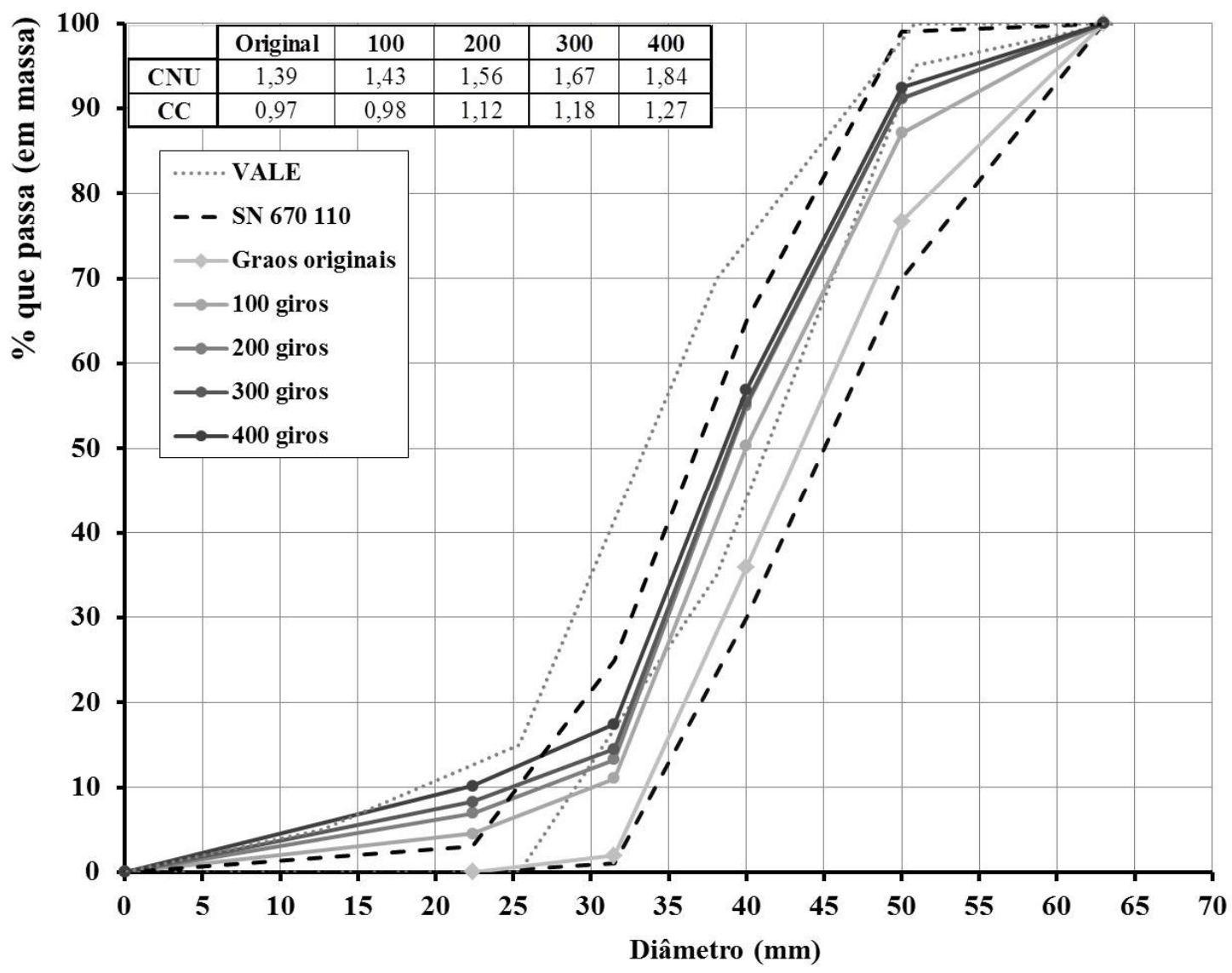

Figura 8. Curvas granulométricas do material submetido à abrasão e seus fatores de gradação

No montante de material mais fino gerado nas frações entre 0 e 22,4 mm e 22,4 e 31,5 mm houve um aumento à medida que o número de giros se elevou. Na fração entre 31,5 e 40,0 mm os resultados não foram conclusivos, indicando um possível valor limite de granulometria em torno dessa faixa granulométrica quanto ao comportamento de degradação do material, enquanto que nas frações granulométricas entre 40,0 e 50,0 mm e, 50,0 e 63,0 mm houve tendência de decréscimo, mais acentuada no caso desta última. 


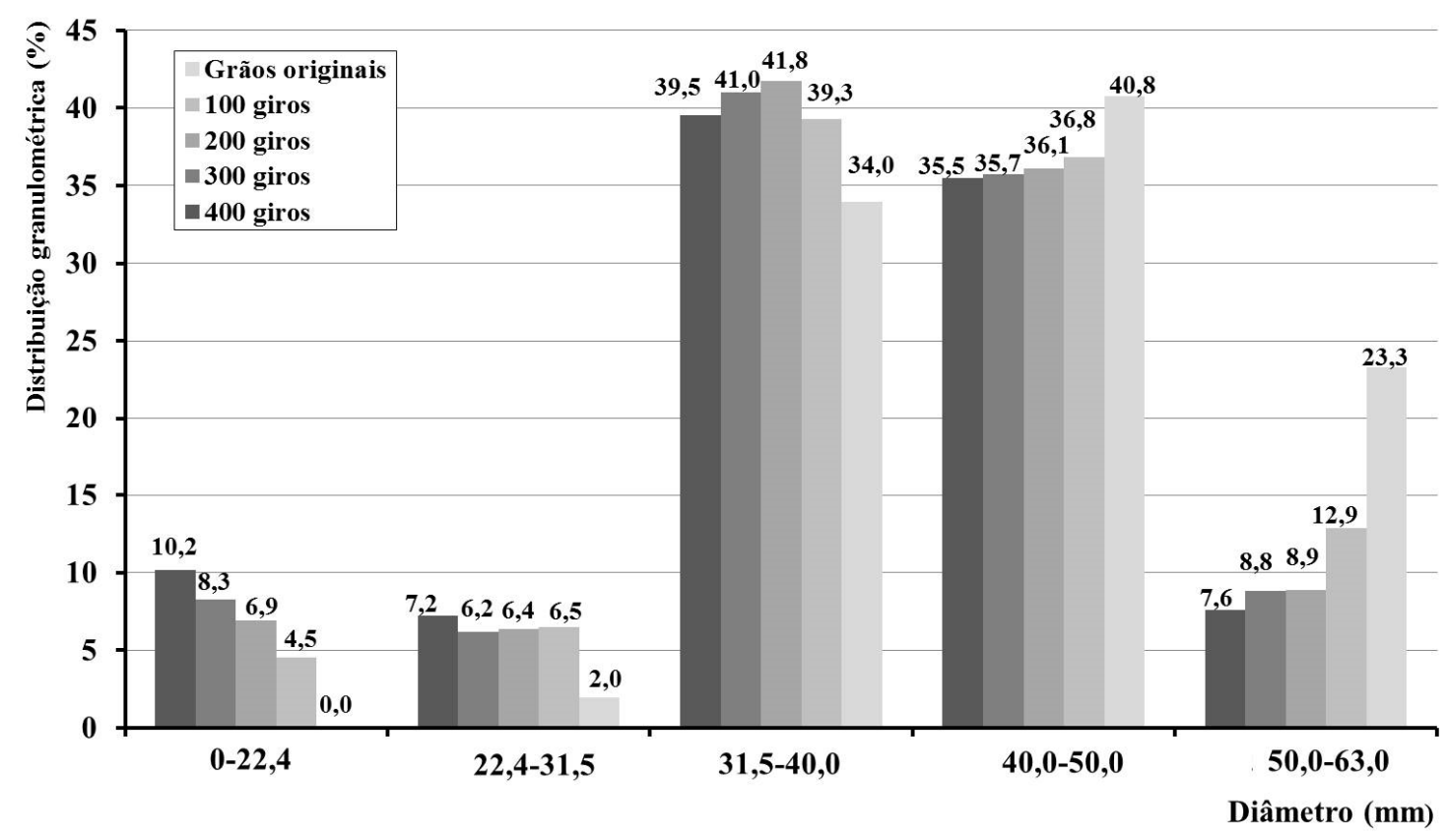

Figura 9. Distribuição das frações granulométricas ao longo do ensaio

A Figura 8 mostra ainda uma tendência de aumento linear nos coeficientes de gradação (CNU e CC), revelando uma perda de parte da uniformidade. Tendência similar foi obtida por Boler et al. (2012) em ensaios LAA também com lastro.

A partir dos resultados dos ensaios granulométricos e de abrasão LAA, além das imagens obtidas e observações visuais, diferentes modos de degradação foram observados (Figura 10):

- Degradação por desgaste - na maioria das partículas $(\approx 64 \%)$, onde foi observada uma tendência de maior perda de massa inicial e subsequente queda, com taxa de arredondamento dos grãos aproximadamente constante;

- Quebra de grão parcial e total - quebra inicial do grão (basicamente arestas) sem criação de uma segunda partícula com tamanho similar, além de quebra total da partícula com geração de um segundo grão com tamanho aproximadamente similar. Posteriormente, em ambos os casos, os novos grãos com seus distintos valores de arredondamento apresentaram uma tendência linear de aumento de degradação por desgaste, caracterizada pela elevação do arredondamento.
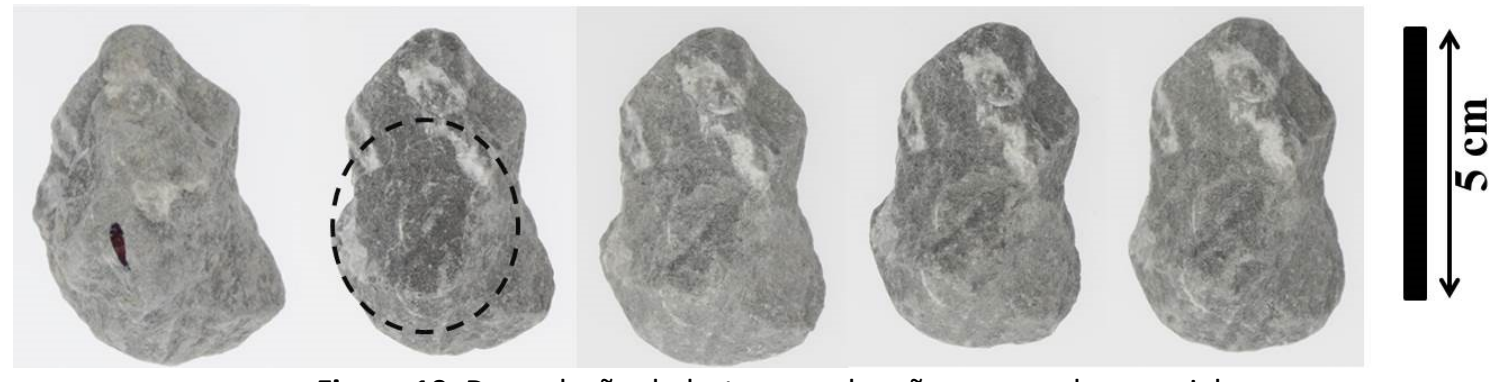

Figura 10. Degradação do lastro por abrasão com quebra parcial

As conclusões obtidas referentes aos modos de degradação vão ao encontro daquelas mencionadas por Raymond e Diyaljee (1979). As Figuras 11 e 12 mostram a evolução do arredondamento de diversos grãos, segundo os modos de degradação por desgaste e quebra completa, com subsequente tendência de degradação por abrasão. Maiores informações e detalhes a respeito dos modos de degradação podem ser vistos em Pires e Dumont (2015). 


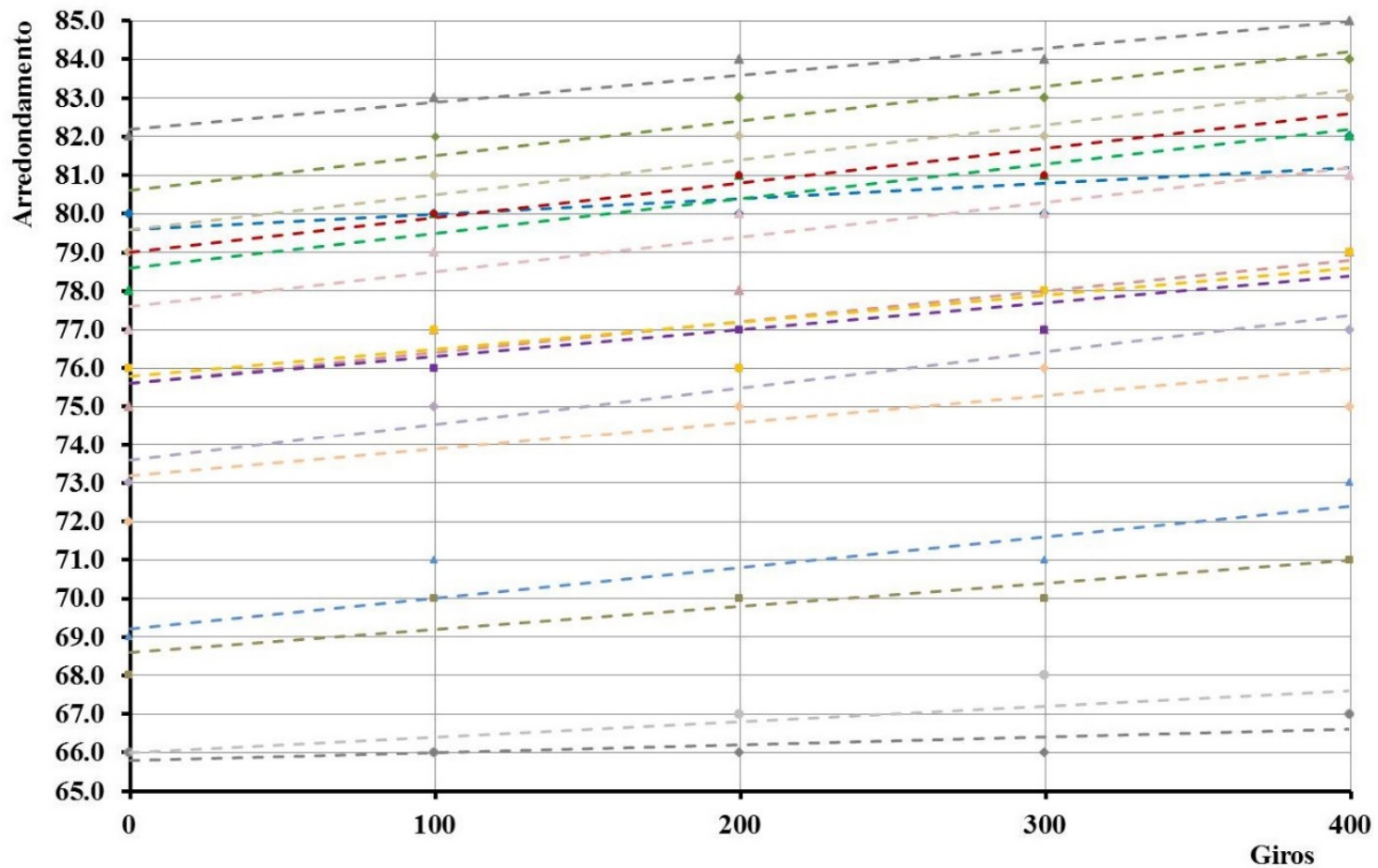

Figura 11. Distribuição das frações granulométricas ao longo do ensaio

A partir dos resultados obtidos, pode-se obter uma relação entre o arredondamento dos grãos e número de giros referentes ao ensaio de abrasão (LAA) (Equação 1).

$$
\mathrm{R}_{1}=\mathrm{A} \cdot \mathrm{RN}+\mathrm{R}_{0}
$$

Em que $\quad \mathrm{R}_{1,0 \text { : }}$ arredondamento final e inicial [-];

$\mathrm{R}_{\mathrm{N}}$ : número de giros; $\mathrm{e}$

A: coeficiente angular (entre $10^{-2}$ e $10^{-3}$ ).

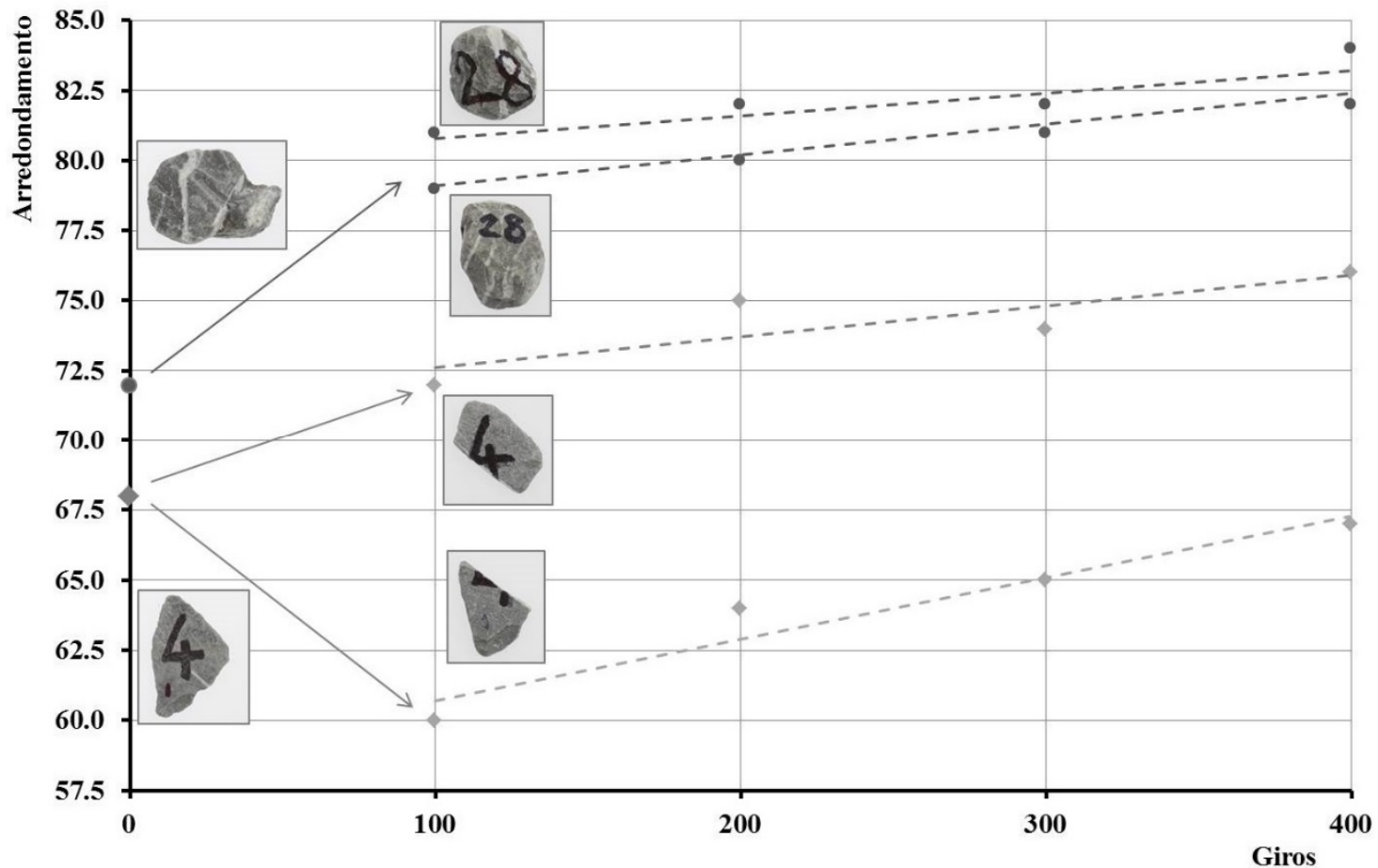

Figura 12. Evolução do arredondamento dos grãos devido à quebra 


\subsubsection{Ensaios em Prensa de Compactação por cisalhamento Giratório (PCG)}

Os resultados obtidos no ensaio são mostrados nas Figuras 13 e 14 concernentes às curvas AREMA № 3 e 24, respectivamente. Observou-se que a curva AREMA № 3, inicialmente (entre 100 e 500 giros) apresentou valores de CNU e CC menores, embora próximos dos mesmos referentes à curva № 24. A curva № 3, porém, a partir de 600 giros, apresentou valores de coeficientes de gradação maiores em relação à curva № 24 em cerca de aproximadamente 40\% (CNU) e 32\% (CC) em relação ao valor total de giros.

Ao comparar os valores de CNU de ambas as curvas granulométricas testadas no intervalo entre 1,5 e 3,0, tal como mencionado por Indraratna et al. (2011) e utilizado em especificações de lastro de diversos países, observa-se que a partir de 400 e 200 giros, as curvas № 3 e 24, respectivamente, não atendem ao requisito preconizado. A partir de 400 giros, o valor de CNU de ambas as curvas (№ 3 e № 24) aumentou significativamente.

A degradação observada mostrou que o material de granulometria № 24 da AREMA, ao final dos ensaios, gerou uma menor quantidade de materiais finos, o que contribui para a preservação das condições mecânicas do material.

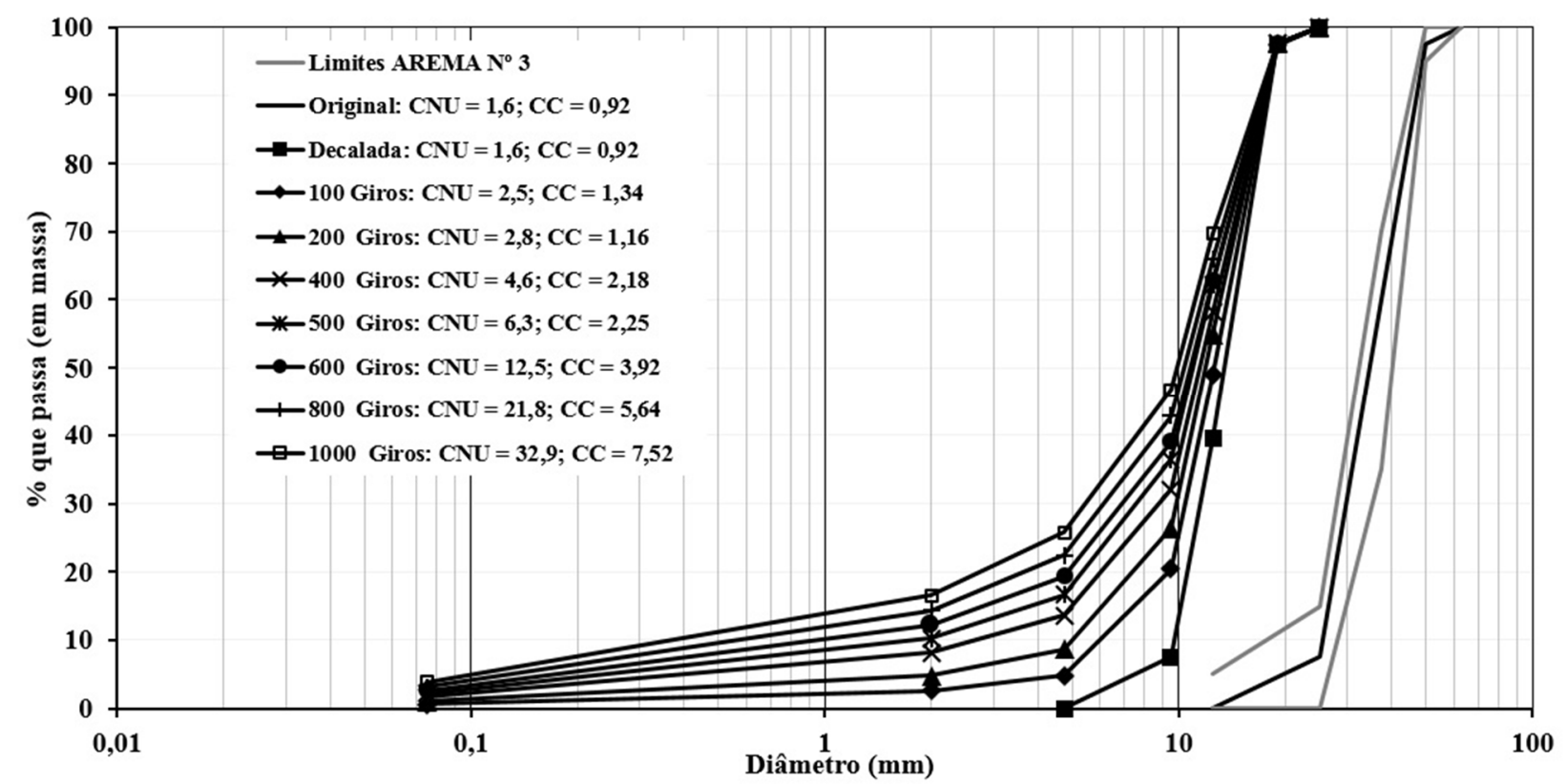

Figura 13. Curvas granulométricas e fatores de gradação de material de lastro, a partir da AREMA $\mathrm{N}^{\circ} 3$ submetida a cisalhamento

Ainda, comparando-se os resultados de CNU dos agregados (origem mineralógica distinta) submetidos à abrasão (LAA) $(22,4 \mathrm{~mm} \leq \mathrm{D} \leq 63,0 \mathrm{~mm})$ com aqueles submetidos aos ensaios de cisalhamento com a PCG $(4,75 \mathrm{~mm} \leq \mathrm{D} \leq 25,0 \mathrm{~mm})$, ao final de 400 giros, observa-se que os valores de CNU referentes ao ensaio de cisalhamento foram significativamente maiores (aproximadamente 250\%). Denota-se, dessa forma, que as partículas ao sofrerem os esforços da prensa giratória apresentaram maior desgaste em comparação com o ensaio LAA.

\section{CONCLUSÕES}

Referente ao ensaio de abrasão Los Angeles (LAA), a degradação ocorreu, em geral, das frações 40,0$50,0 \mathrm{~mm}$ e $50,0-63,0 \mathrm{~mm}$ para aquelas $0-22,4 \mathrm{~mm}$ (material fino, colmatante) e $22,4-31,5 \mathrm{~mm}$. Os resultados referentes à fração 31,5-40,0 mm foram inconclusivos por não apresentarem uma tendência única ao longo do acúmulo de giros ensaiados. 


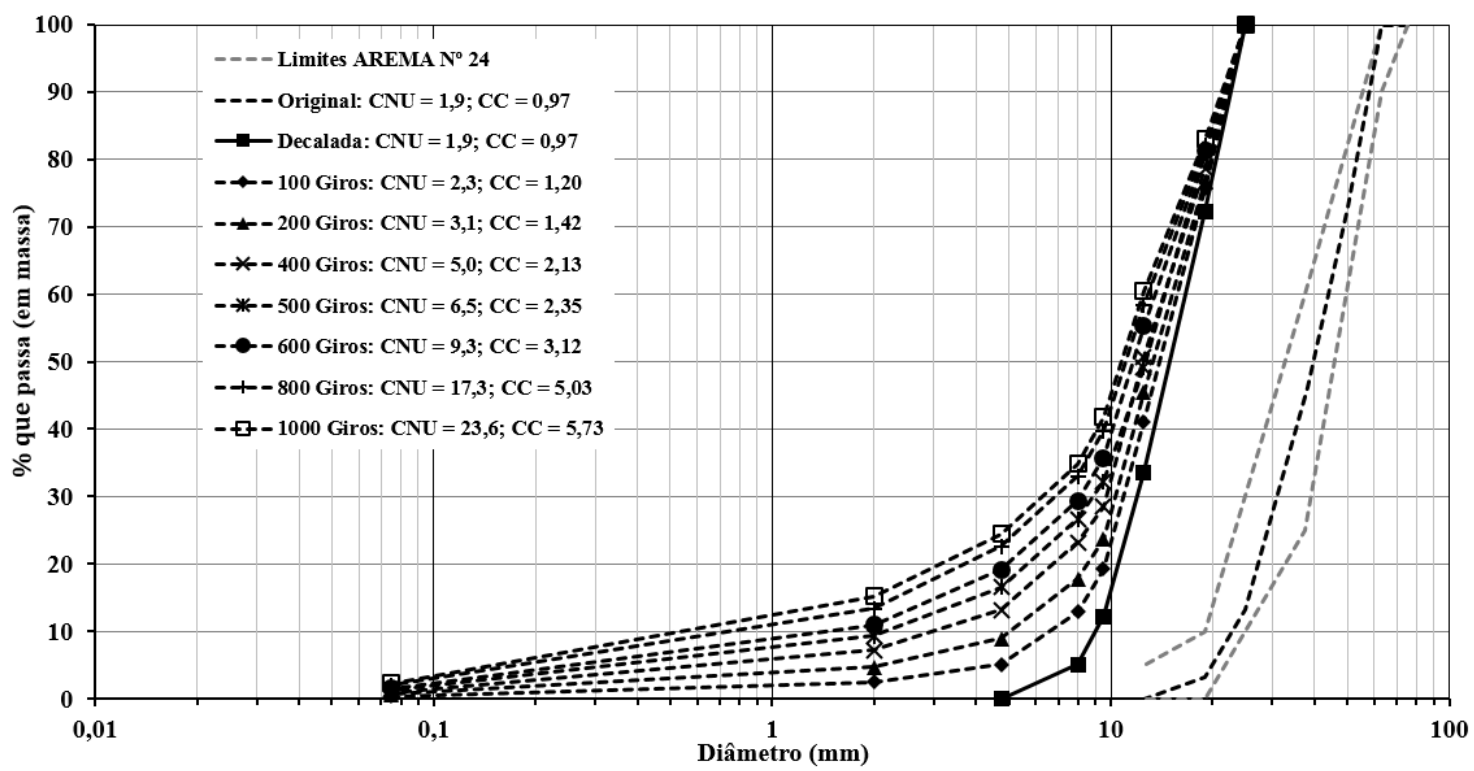

Figura 14. (Curvas granulométricas e fatores de gradação de material de lastro, a partir da AREMA N 24 submetida ao cisalhamento

Ao longo dos estágios dos ensaios, diferentes modos da degradação do lastro relacionados à abrasão e à quebra foram detectados. 0 fenômeno da abrasão se mostrou presente em todos os modos de degradação, enquanto a quebra ocorreu de maneira parcial ou completa logo no início dos ensaios.

A abrasão por desgaste provocou um aumento aproximadamente linear do arredondamento em função do aumento de giros no ensaio LAA. Por outro lado, a quebra do grão foi caracterizada pela ruptura das arestas dos grãos ou mesmo por uma maior parte deste, resultando em alguns casos em novos valores de arredondamento nos grãos envolvidos. Tais grãos, após a ruptura, passaram a seguir uma tendência de abrasão.

O método utilizado baseado em ensaios de abrasão LAA e análise de imagens dos grãos permitiu observar a degradação do lastro, especialmente nos casos de degradação por abrasão. Ademais, recomenda-se a realização de ensaios triaxiais em escala real (sem decalagem), a fim de verificar a degradação do lastro em termos qualitativos e quantitativos (modos de degradação).

Quanto ao ensaio de cisalhamento, os resultados mostraram valores de CNU maiores no caso da curva granulométrica AREMA № 3, indicando, dessa forma, desgaste mais elevado desse material em relação à curva granulométrica da AREMA № 24.

Os resultados dos coeficientes de gradação observados ao longo de ambos os ensaios realizados mostraram valores consideravelmente diferentes. Tal fato se deu em função da diferença entre os testes no tocante ao modo e intensidade dos esforços aplicados ao material. De singular importância seria um estudo a se verificar a congruência dos resultados para com aqueles obtidos em amostras coletadas in situ, submetidas não somente a períodos de acúmulo de tráfego, mas também ações de socaria.

\section{REFERENCIAS}

AAR (1989) Ballast Renewal Model User's Manual, Report No R-701, Association of American Railroads, USA.

AREMA (2013) Manual for Railway Engineering, American Railway Engineering and Maintenance of Way Association, Vol. 1-4. Aursudkij, B. (2007) A Laboratory Study of Railway Ballast Behavior under Traffic Loading and Tamping Maintenance, PhD.

Thesis, University of Nottingham, UK, 234 p. ID: 10321.

Boler, H.; M. Wnek e E. Tutumluer (2012) "Establishing Linkages between Ballast Degradation and Imaging Based Aggregate Particle Shape, Texture and Angularity Indexes", Advances in Transportation Geotechnics II, pp. 186-191.

Esveld, C. (1993) Uniform Ballast Quality Assessment Criteria, Rail Engineering International Edition, № 2, pp. 11-13. ISSN: 0141-4615 
Fortunato, E. M. C. (2005) Renovação de Plataformas Ferroviárias - Estudos Relativos à Capacidade de Carga, PhD Thesis, University of Porto, 628 p. ID: 10216/11441

Indraratna, B e W. Salim (2003) Deformation and Degradation Mechanics of Recycled Ballast Stabilised with Geosynthetics, Soils and Foundations, Vol. 43, № 4, pp.35-46. DOI: 10.3208/sandf.43.4_35.

Indraratna, B.; J. Lackenby e D. Christie (2005) Effect of Confining Pressure on the Degradation of Ballast under Cyclic Loading, Géotechnique 55, № 4, pp. 325-328. DOI: 10.1680/geot.55.4.325.65490.

Indraratna, B.; P. K. Thakur e J. S. Vinod (2010) Experimental and Numerical Study of Railway Ballast Behaviour under Cyclic Loading, International Journal of Geomechanics, № 10, pp. 136-144. DOI : 10.1061/(ASGE)GM.1943-5622.0000055.

Indraratna, B.; W. Salim e C. Rujikiatkamjorn (2011) Advanced Rail Geotechnology - Ballasted Track, CRC press, 414 p. ISBN:9781138072893.

Ionescu, D. (2004) Evaluation of the Engineering Behaviour of Railway Ballast, PhD Thesis, University of Wollongong, Australia, $483 \mathrm{p}$.

Ionescu, D. (2005) Ballast Degradation and Measurement of Ballast Fouling, RTR 2, Eurailpress, pp. 12-18. ISBN: 0947644547.

Klincevicius, M. G. Y. (2011) Estudo de Propriedades, de Tensões e do Comportamento Mecânico de Lastros Ferroviários. Dissertação de Mestrado, Universidade de São Paulo, São Paulo, 171 p. DOI: 10.11606/D.3.2011.tde-27032012-121114

Lekarp, F.; U. Isacsson; e A. Dawson (2000) State of the art. I: Resilient Response of Unbound Aggregates, Journal of Transportation Engineering, Vol. 126, No 1, pp 66-75. DOI: 10.1061/(ASCE)0733-947X(2000)126:1(76).

Lichtberger, B. (2005) Track Compendium - Formation, Permanent Way, Maintenance, Economics, Eurail Press, 635 p. ISBN: 9783777103204

Lobo-Guerrero, S. e L. Vallejo (2005) Discrete Element Method Analysis of Railtrack Ballast Degradation During Cyclic Loading , Granular Matter No 8 (3), pp. 195-204. DOI: 10.1007/s10035-006-0006-2

Merheb, A. H. M. (2014) Análise Mecânica do Lastro Ferroviário por Meio de Ensaios Triaxiais Cíclicos. Dissertação de Mestrado, Universidade de São Paulo. São Paulo, p. 148. DOI: 10.11606/D.3.2014.tde-20052015-160602

Mvelase, G. M.; J. K. Boateng e P. J. Grabe (2012) Application of Laser Based Technology to Quantify Shape Properties of Railway Ballast, 31st Southern African Transp. Conf., pp. 243-254. ISBN: 978-1-920017-53-8

Neidhart, T. e G. Schulz. (2011) Dynamic Stability of Railway Tracks - Dystafit, an Innovation in Testing, GEORAIL International Symposium Railway Geotechnical Engineering, France, pp. 335-346.

Nurmikolu, A. (2005) Degradation and Frost Susceptibility of Crushed Rock Aggregates Used in the Structural Layers of Railway Track, PhD Thesis, Tampere University of Technology, 325 p. ISBN: 952-15-1481-7.

Oda, M. e K. Iwashita (1999) Mechanics of Granular Materials: An Introduction, A. A. Balkema. ISBN: 9789054104612

Paderno, C. (2010) Ballast Behavior Under Action of Tamping and Railway Traffic, PhD Thesis, EPFL, Suíça, 186 p. DOI: 10.5075 /epfl-thesis-4697

Perales, R.; G. Saussine; N. Milesi e Y. Descantes (2011) On the Damaging Effects of the Ballast Tamping Operation, 9th World Congress on Railway Research, $10 \mathrm{p}$.

Pires, J. J. e A. G. D. Dumont (2015) Railway Ballast Degradation, STRC - 15th Swiss Transport Research Conference, Ascona, 25p.

Raymond, G. P. e V. A. Diyaljee (1979) Railroad Ballast Load Ranking Classification, Journal of the Geotechnical Engineering, ASCE 105, No10, pp. 1133-1153. ISSN: 1090-0241

Raymond, G. P. (1985) Research on Railroad Ballast Specification and Evaluation, Transportation Research Board, pp. 1-6. ISBN: 0309038162.

Röthlisberger, F.; J. Cuénoud; L. Chastan; J. Däppen e E. Kuerzen (2006) Compressive Strength of Aggregates on the Stack, VSS 1993/012, 59 pages.

Ruth, B. E. e M. Tia (1998) Aggregate Degradation Testing by Gyratory Testing Machine. Transportation Research Record 1619, No 98-0062, 8 p. DOI: 10.3141/1619-01.

Selig, E. T. e D. L. Boucher (1990) Abrasion Tests for Railroad Ballasts, Geotechnical Testing Journal, Vol. 13, Issue 4, pp. 301311. ISSN: 0149-6115.

Selig, E. T. e J. M. Waters (1994) Track Geotechnology and Substructure Management, Thomas Telford Services Ltd. DOI: 10.1680/tgasm.20139.fm

Sevi, A. S. (2008) Physical Modeling of Railroad Ballast using Parallel Gradation Scaling Technique within the Cyclical Triaxial Framework. PhD Thesis, Missouri University of Science and Technology, 137p.

SN 670-110/EN 13450 (2002) Granulats pour Ballasts de Voies Ferrées.

Terzagui, K e R. B. Peck (1962) Soil Mechanics, Ao livro técnico S.A., 659 p.

VALE (2011) Comunicação pessoal.

Wadel, A. D. (1932) Volume, Shape and Roundness of Quartz Particles, The Journal of Geology, Vol. 40, No 5, pp.443-451. DOI: $10.1086 / 624298$. 